\title{
"Detection of Early Pregnancy Loss Using Vaginal Blood Alpha-Fetoprotein in the Pipeline" - A Short Commentary
}

\author{
Kulvinder Kochar Kaur ${ }^{1 *}$, Gautam Allahbadia ${ }^{2}$ and Mandeep Singh ${ }^{3}$ \\ ${ }^{1}$ Scientific Director, Dr. Kulvinder Kaur Centre for Human Reproduction, India \\ ${ }^{2}$ Scientific Director, Rotunda - A Centre for Human reproduction, India \\ ${ }^{3}$ Consultant Neurologist, Swami Satyanand Hospital, India
}

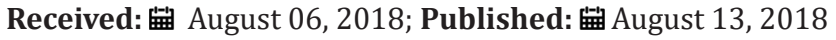

*Corresponding author: Kulvinder Kochar Kaur, Scientific Director, Dr. Kulvinder Kaur Centre for Human Reproduction, India

\section{Commentary}

\section{Vaginal Bleeding is a Common Presentation in Early Spontaneous Abortion}

Roughly $22 \%$ of all pregnancies end in an abortion [1]. This rate goes up to as much as $75 \%$ in pregnancies occurring in advanced age. Normally once women seek counselling with bleeding in early pregnancy mostly the standard method of finding viability has been clinical evaluation, doing an ultrasonography along with quantitative HCG levels and repeated USG for confirmation of a missed abortion causing loss of time and emotional sequelae [2]. Robinson et al. [2] quoted that stress and anxiety is worst at the time of initial knowledge than the depression that follows the final miscarriage [2]. Garcia [3] reviewed the risk factors for these. Importance of making an early diagnosis is that one can stop the medications like P or oral anticoagulants, while those who have an ongoing IUP, one can reassure the patient and observe her medically.

Recently based on the physiological knowledge that alpha protein (AFP) is produced by yolk sac and later on by the fetal liver [4], as early as the $5^{\text {th }}$ week of gestation, AFP can be measured from the embryonic tissue. In fetal serum AFP is $>=1000$ times higher than the maternal serum [5]. Thus Mor [6] hypothesized if AFP concentration in vaginal blood which contains dissolved fetus tissue is higher than AFP concentrations in maternal serum. Thus, they tried to find if relatively high AFP concentrations in early 1st trimester or early second trimester vaginal blood will confirm the presence of an IUP which has failed i.e. a missed abortion or incomplete abortion since it contains dissolved fetal tissues [6].

Having a commercial assay of AFP already available, they used it to test it as a potential biomarker. Marked difference in the ratio of vaginal blood AFP/serum AFP was found in women who had failed IUP's as compared to ongoing pregnancies that had non related bleeding like in post cerclage placement. They got a $100 \%$ sensitivity along with $87 \%$ specificity, along with AFP ratio in blood to serum showing significant diagnostic characteristics with a ratio of $<=4.3$ consistent with threatened abortion and that $>13.4$ with a failed IUP. Thus, they concluded these vaginal blood AFP could act as a novel biomarker for early pregnancy failure, since it can be obtained early and give immediate results [6].

However, the authors themselves point out limitations, namely it can't differentiate the source of bleeding like in nonpregnant sources like cervical infection. Also, an overlap exists in the AFP values between women who had definite spontaneous abortion and those having threatened abortion. Also, patients presenting with massive hemorrhage will have diluted AFP values giving falsely low AFP values. Thus, a small number of patients will not be getting a prompt diagnosis and need follow up just as the earlier cases. Further since the authors don't have data on deliveries or potential pregnancy related complications in the women having threatened abortion as they were not further followed up, they can't give ultimate pregnancy outcome.

Important Is that AFP concentrations in vaginal blood might find a potential need in the work up of pregnancies having unknown location, mainly ruling out ectopic pregnancy. It is known that a single HCG measure along with serial HCG measures has limited accuracy in diagnosing ectopic pregnancy that is below the USG discriminatory zone [7]. Confirmation of failed IUP and thereby exclusion of ectopic pregnancy has been done using OPD endometrial aspiration using manual vacuum aspirator devices as other methods of endometrial sampling for the presence of chorionic villi has not proven to have accuracy. This might add an advantage if vaginal AFP concentrations could additionally prove a noninvasive method having no risk and confirm failed IUP even prior to ultra sound visualization and thus excluding an ectopic pregnancy.

Still longer follow-ups in a greater number of patients carried out prospectively needs to be done to establish this method to diagnose nonviability of pregnancy on same day using vaginal 
blood AFP as an established method for diagnosing nonviability of IUP in patients presenting with vaginal bleeding in emergency presentation.

\section{References}

1. Zinaman MJ, Clegg ED, Brown CC, O’Connor J, Stevens SG (1996) Estimates of human fertility and pregnancy loss. Fertil Steril 65(3): 503509.

2. Robinson GE (2013) Pregnancy loss. Best Pract Res Clin Obstet Gynecol 28: $168-178$.

3. Gracia CR, Sammel MD, Chittans J, Hummel A, Shaunk A, et al. (2005) Risk factors for spontaneous in early symptomatic first trimester pregnancies. Obstet Gynecol 106(5-1): 993-999.

ISSN: 2574-1241

DOI: 10.26717/BJSTR.2018.07.001566

Kulvinder Kochar Kaur. Biomed J Sci \& Tech Res

(C) This work is licensed under Creative

Submission Link: https://biomedres.us/submit-manuscript.php
4. Saranakou A, Protonotariou E, Rizos D (2007) Tumor markers in biological fluids associated with pregnancy. Crit Rev Clin Lab Sci 44(2): 151-178.

5. Mizejewsky GJ (2003) Levels of alpha feto protein during pregnancy and early infancy in normal and diseased states. Obstet Gynecol Surv 58(12): 804-826.

6. Mor A, Tal-Reshel T, Haberman S, Kalgi B, Nasab S, et al. (2018) Same day confirmation of intrauterine pregnancy failure in women with first and early second trimester bleeding. Fertil Steril 109(6): 1060-1064.

7. Seeber BE (2012) What serial HCG can tell you, and cannot tell you, about an early pregnancy. Fertil Steril 98(5): 1074-1077.

$\begin{array}{ll}\text { BIOMEDICAL } & \text { Assets of Publishing with us } \\ \text { RESEARCHES } & \text { Global archiving of articles } \\ & \text { - Immediate, unrestricted online access } \\ & \text { - Rigorous Peer Review Process } \\ & \text { - Authors Retain Copyrights }\end{array}$

